\title{
Акмеологический анализ индивидуальной профессиональной успешности менеджеров среднего звена энергетического комплекса
}

\section{Шаповалова В.А., Криченко Е.В.}

Статья посвящена психолого-акмеологическомуисследованию менеджеров среднего звена Новочеркасской государственной районной электростанции (НчГРЭС). Анализируется теоретические представления о профессиональной успешности. Приводятся некоторые результаты эмпирического исследования, в котором выявлены общие профессионально важные качества, обеспечивающие успешность деятельности руководящего состава.

Ключевые слова: профессиональная успешность, менеджер среднего звена, концепция профессионального становления, деятельность, профессионально важные качества.

Сегодня практика управления и стимулирования трудовой активности персонала во многом опирается на определение величины индивидуального вклада работников в успех организации. Это предполагает выделение объективных показателей профессиональной успешности. Однако возможность ее прогноза, также как и осуществление профотбора, расстановки кадров, формирования кадрового резерва зависит уже не столько от знания индивидуального рейтинга по данным показателям, сколько от учета личностных факторов, значимых для решения задач профессиональной деятельности.

Энергетическая промышленность является одной из самых важных для развития экономики государства. Государственные районные электростанции (ГРЭС) снабжают электроэнергией огромное количество объектов, в том числе и объекты оборонного комплекса. Обслуживающий персонал ГРЭС, работая на сложном, стратегически важном объекте ежедневно отвечает за наличие электроэнергии на большой территории. В этой ситуации особо необходимо осуществление эффективного руководства ГРЭС по всем направлениям: от качественного управления производственным процессом до отбора персонала и воспитания кадров.

Как показал анализ научной литературы, теоретической базой концепции профессионального становления личности на современном этапе стало фундаментальное представление о динамическом характере психического, о необходимости изучения психической жизни личности в форме процесса постоянного взаимодействия человека с окружающей действительностью, разработанное С.Л. Рубинштейном и получившее развитие в работах К.А. Абульхановой-Славской, Л.И. Анцыферовой, Б.Ф. Ломова, В.Д. Шадрикова.

Успешность деятельности предстает в исследовании как характеристика деятельности, включающая в себя производительность труда, качество продукции, скорость, безошибочность действий и т.д. Успех в профессиональной деятельности проявляется, прежде всего, в достижении работником значимой цели 
и преодолении или преобразовании условий, препятствующих достижению цели. Так, с точки зрения одной цели одно и то же действие может быть успешным, с точки зрения другой цели - действие может характеризоваться как нейтральное (безразличное). С психологической точки зрения успех - это переживание состояния радости, удовлетворение от того, что результат, к которому человек стремился в своей деятельности, либо совпал с его надеждами, ожиданиями (или, строго говоря, с уровнем притязаний), либо превзошел их. На базе этого состояния могут формироваться устойчивые чувства удовлетворения, формируются новые, более сильные мотивы деятельности, меняется уровень самооценки, самоуважения.

Понятие эффективности применяется для оценки успешности профессиональной деятельности. А.К. Маркова для оценки эффективности труда наряду с другими объективными показателями относит качество и надежность [5]. В.Д. Шадриков, реализуя функциональный подход к деятельности, выдвигает формулу нормативных способов социальной деятельности, отвечающих характеристике деятельности как труда, параметрами которой являются производительность, качество и надежность [7]. Используемое М.А. Дмитриевой для оценки профессиональной деятельности понятие «профессиональная успешность» очень близко к рассмотренному выше понятию «Эффективность». Успешность деятельности в данном случае включает продуктивность, производительность труда, качество продукции, надежность действий. При возможности количественной оценки и высокой степени надежности показателем успешности может служить уровень сложности решаемой задачи. Наряду с указанными показателями успешности, как подчеркивает исследователь, «следует учитывать и нервно-психические затраты, необходимые для достижения цели, а также степень удовлетворенности работника своим трудом» [3].

Новочеркасская Государственная районная электростанция (НчГРЭС), на базе корой мы проводили исследование, - тепловая электрическая станция в поселке Донской города Новочеркасска Ростовской области Южного федерального округа. НчГРЭС является основным источником генерации электроэнергии в Ростовской области, обеспечивающим электроэнергией наиболее промышленно развитую юго-западную часть области, в том числе, объекты оборонного комплекса. Являясь столь важным стратегическим объектом нашего региона, НчГРЭС испытывает необходимость в высокопрофессиональных кадрах. Условия сложной и ответственной деятельности оказывают определенное влияние на сотрудников электростанции. В этой ситуации остро встает вопрос формирования руководящего состава менеджеров среднего звена и кадрового резерва с использованием научного психологического подхода.

В исследовании приняло добровольное участие 120 человек, из них 76 \% мужчин и $24 \%$ женщин. На основе аналитических профессиограмм нами были выделены общие профессионально важные качества, обеспечивающие успешность деятельности руководителей среднего звена НчГРЭС. Затем в соответствии со спецификой деятельности, отраженной в профессиограммах, были выделены специфические для той иной должности руководителя профессионально важные качества. 
Как показал анализ профессиональной деятельности работников энергетического комплекса, эта сфера труда достаточно сложна и осуществляется в специфических условиях, связанных с повышенной ответственностью, посменной работой, осознанием глубины последствий аварийных ситуаций в масштабах региона. Эта сфера деятельности характеризуется также достаточно широким рядом факторов технического характера, негативно влияющего на общее, соматическое и эмоциональное состояние работников.

У менеджеров среднего руководящего звена ГРЭС проявляются общие устойчивые характерологические личностные особенности, которые можно рассматривать как профессионально важные качества, используемые для профессионального отбора и для формирования профессионального резерва. Специфические профессионально важные качества для начальников цехов: способность к обеспечению условий труда других людей, способность к организации обучения и инструктажей других людей, способность создавать условия для повышения квалификации, профессионального мастерства других людей. Специфические профессиональные важные качества для заместителей начальников цехов: умение анализировать символическую информации, знание профессионально важных качеств, необходимых для выполнения работы в данном подразделении, способность устанавливать истинные причины инцидентов, несчастных случаев, аварий и т.п. Специфические профессиональные важные качества для начальников смен: способность создавать условия для повышения квалификации, профессионального мастерства других людей, умение поддерживать бдительность в течение смены, самостоятельность в принятии и реализации решений. Специфические профессиональные важные качества для мастеров: умение анализировать символическую информацию, способность оперативно выявлять истинные причины инцидентов, несчастных случаев, аварий и т.п., умение оперативно прогнозировать, предвидеть результаты технологического процесса.

Наиболее значимыми для профессионального отбора являются такие качества как умение мотивировать работников к выполнению приказов и поручений, способность управлять собой в стрессовой ситуации, стремление к самообучению и саморазвитию, настойчивость в достижении цели, умение непротиворечиво, последовательно, рационально обрабатывать оперативную информацию. Как показало исследование, в качестве важного фактора успеха мотивационной сферы выступает смысловая оценка стимулов трудовой активности. Так, сама трудовая деятельность не значима с точки зрения реализации мотивов кооперации и конкуренции, В то время как коллектив выступает скорее не как сфера взаимодействия, а как объект воздействия. Успешность связана с ориентацией на поиск личностного смысла результата трудовой деятельности, хотя деньги не являются основной целью достижений в труде.

Соответственно полученным данным можно сделать вывод, что одни и те же личностные качества, влияющие на успешность профессиональной деятельности, присущие как низкоуспешным, так и высокоуспешным руководителям, различаются не только разной степенью выраженности, но имеют различные структурные связи и свое особое содержание. 
Если говорить о портретах высоко- и низкоуспешных руководителей среднего звена ГРЭС, то низкоуспешные характеризуются эмоциональными и коммуникативными связями с профессионально важными личностными качествами. У высокоуспешных руководителей содержание связей с профессионально важными личностными связями носит иной характер: например, эти связи с интеллектуальными качествами, доминантностью-конформностью. Количество связей низкоуспешных и высокоуспешных руководителей различно: у высокоуспешных руководителей их меньше. Возможно, это связано с жестко закрепленной ролью руководителя на производстве и направленностью на задачу, а не на человека.

Проведенный факторный анализ позволил выявить различия в структуре взаимосвязей смыслообразующих мотивов и мотивов-стимулов по данным методики Кокуриной в группах высоко и низкоуспешных руководителей. В группе низкоуспешных руководителей фактор образовали такие переменные как: мотив-стимул "коллектив» со смыслообразующим мотивом «конкуренция»на одном полюсе (вес по фактору - 0,853), и мотив-стимул «коллектив» со смыслообразующим мотивом «кооперация» - на другом (вес по фактору + 0,82). Данный фактор интерпретировался как «Я - Мы в рамках управления коллективом». Это позволяет судить не только о количественных различиях, заключенных в выраженности мотивов, но и о структурных различиях, отражающих связи между мотивами. Полученные данные раскрывают сферу отношений, в которой реализуется смыслообразующий мотив. Так для низкоуспешных руководителей среднего звена, стимулом к деятельности является сфера отношений в коллективе, а смыслом - конкуренция или кооперация. Высокоуспешных стимулирует к деятельности прежде всего сам труд управления с утилитарно-прагматическим мотивом добиться максимума эффективности либо труд стимулируется кооперацией с членами коллектива.

Проведенное исследование показало актуальность поставленной проблемы. Дальнейшая разработка этой проблемы позволит сформулировать стандарты проведения качественного профессионального отбора и формирования кадрового резерва на всех предприятиях энергетического комплекса.

\section{Литература}

1. Абульханова-Славская К.А. О субъекте психической деятельности. - М., 1973.

2. Анциферова Л.И. Личность в трудных жизненных условиях // Психологический журнал. - 1994. - № 1.

3. Дмитриева М.А. Практикум по психологии менеджмента и профессиональной деятельности. - Санкт-Петербург, 1991. - 448 с.

4. Ломов Б.Ф. Общение и социальная регуляция поведения индивида // Психологические проблемы социальной регуляции поведения. - М., 1976.

5. Маркова А.К. Психология профессионализма. - М.: Знание, 1996. 308 с.

6. Рубиншейн С.Л. Основы общей психологии. В 2-х т. - Т. 1. - М., 1989. - 488 с.

7. Шадриков В.Д. Деятельность и способности. - М.: Изд-во «Логос», 1994. - 315 с. 